\title{
OPTIMIZATION OF A SMALL SOLAR CHIMNEY
}

\author{
Janaína Oliveira Castro Silva, Cristiana Brasil Maia*
}

\author{
Pontifical Catholic University of Minas Gerais (PUC Minas), Department of Mechanical Engineering, Av. Dom \\ José Gaspar, 500. Belo Horizonte, 30535-901, Brasil \\ * corresponding author: cristiana@pucminas.br
}

\begin{abstract}
An optimization study to maximize the exergy efficiency of a small-scale solar chimney was carried out. Optimization variables include collector diameter $\left(D_{c}\right)$, collector height $\left(H_{c}\right)$, tower height $\left(H_{t}\right)$, and tower diameter $\left(D_{t}\right)$. Models from the literature were used to predict environmental and airflow parameters. Exergy efficiency and solar chimney efficiency were determined, on an hourly basis, for a one-year period. The model was simulated using the EES software. Two methods of optimization were used, the method of conjugate directions and the method of variable metric, both providing similar results. Results were compared to the results from an experimental prototype, and it was found that the energetic and exergetic efficiency were significantly improved. The analysis indicated that the height and diameter of the chimney and collector are the most important physical variables in the design of a solar chimney. For both methods, it was found that the maximum exergy efficiency was obtained with a collector height of $0.5 \mathrm{~m}$, a collector diameter of $30 \mathrm{~m}$, a tower diameter of $1 \mathrm{~m}$, and a tower height of $17.8-18.8 \mathrm{~m}$. The exergy efficiency was $44 \%$.
\end{abstract}

KEYWORDS: Solar chimney, optimization, conjugate directions, variable metric.

\section{INTRODUCTION}

In the last few decades, global population and global consumption of energy have increased significantly. The rapid depletion of natural fuel resources, rising fossil fuel costs and environmental damages have increased the search for renewable energy sources. Solar energy arises as a non-pollutant, abundant and renewable source. Solar chimney (or solar updraft) power plant is a device that uses solar radiation to drive air for electricity generation. It consists mainly of a solar collector, a tower and turbine generators. Solar radiation passes through the transparent solar collector and reaches the ground, which works as an absorber. Part of the heat is stored in the deeper layers of the ground, and part is released to the air under the solar collector. The buoyancy acts as the driving force. The air flows toward the tower and drives the turbine. The main use of the solar chimney is power generation [1, 2], but it can also be used for food drying $3-5$. Recently, some authors started to develop mathematical simulations to assess the viability of solar chimneys to be used combined with desalination systems, to simultaneously generate power and produce freshwater [6 11], as reviewed by [12, 13].

Geometric parameters play an important role in the performance of solar chimneys. Several authors studied the influence of geometry on the performance of the device. For fixed values of tower height and collector diameter, the collector inlet opening, the collector outlet diameter and height, the tower inlet opening and the chimney divergence angles were varied as an attempt to improve the performance of small scale solar chimney power plants using Computational Fluid Dynamics (CFD) [14, 15]. An experimental study of the variation of the tower height, inlet collector height, and collector materials was performed by [16, 17] for a small solar chimney. The experimental prototype was used in the validation of a CFD analysis to increase the fluid velocity and the solar chimney efficiency, varying the tower height, the collector diameter and the collector entrance. A 3D numerical model incorporating a radiation model, a solar load model, and a real turbine was developed by [18, using the commercial code Ansys Fluent. The Manzanares dimensions were used as a reference. The influence of the tower height, collector diameter, and area ratio of chimney entrance over chimney exit was studied by $[19$ using the Ansys Fluent CFD code. The tower height ranged from $100 \mathrm{~m}$ to $300 \mathrm{~m}$ and the collector diameter ranged from $5 \mathrm{~m}$ to $15 \mathrm{~m}$. A CFD model based on a finite volume method was also used by 20 , to evaluate the effect of geometric parameters on temperature, velocity, pressure distribution, efficiency and output power in a solar chimney. The tower height and collector radius ranged from $20 \mathrm{~m}$ to $500 \mathrm{~m}$, using prescribed values for the heat flux. According to the literature, the tower height and the solar collector diameter are the parameters that affect the performance the most [21, 22. Numerical analyses were developed by several researchers to describe the airflow parameters inside the solar chimney [23, 24], and to describe the entropy generation inside the device [25]. The influence of daily solar radiation and ambient temperature on the distribution of temperature, velocity and pressure was evaluated by [26].

Optimization techniques have been used to determine the best geometry for a given purpose, such as the highest efficiency, the highest power output, or 
the minimum expenditure. Global analysis models and CFD were used to describe the airflow inside the solar chimney. In [27], an energy balance was developed, using meteorological data (solar radiation, ambient air temperature, and wind velocity) and Manzanares dimensions as a reference. Subsequently, the authors used the developed model to maximize the total output power. A multi-objective optimization was performed by [28, 29]. The authors used the collector diameter and the tower height and diameter as design parameters and prescribed values of solar radiation to maximize the power output and minimize the capital cost of components [28] and minimize the expenditure and maximize total efficiency and power output [29], using a global analysis.

A finite-difference approximation was used by [30] to solve the mathematical model of a solar chimney and to minimize the plant expenditure, using Manzanares dimensions as reference. A 2D numerical simulation and a sensitivity analysis were developed by 31, using Finite Volume Method to maximize the power output of a solar chimney, also using Manzanares as reference. The maximization of the power output was also described by 32 . The authors developed a 1D asymptotic fluid dynamic model, with the differential equations solved using Matlab.

CFD analyses were developed by [33] and 34. In both works, the Reynolds averaged Navier Stokes equations were solved using a constant heat flux as boundary condition and Manzanares dimensions as reference. The objective function of 33 ] was the maximization of the power density, while the objective function of 34 were the performance parameters of the airflow temperature, pressure and velocity profiles. To extract the maximum output from the wind, [35] performed an optimization analysis of small scale wind turbine blades for a solar chimney power plant, under various wind velocity ranges.

Optimization techniques were also used in the solar chimney combined with other applications. A combined solar chimney for desalination and power generation was studied by [11. The objective function was the ratio of the costs of the collector, tower and desalination, and the prices of electricity and freshwater production. A solar chimney power plant integrated to Tehran's waste-to-energy was studied by [36], attempting to maximize the exergy efficiency and minimize the total cost rate. An optimization of a solar chimney power plant integrated with transparent photovoltaic cells and desalination was performed by [37. The objective function was to maximize the utilization of solar energy, enhancing the overall plant efficiency.

From the literature review, it can be seen that the majority of works use Manzanares prototype as a reference for the dimensions. It is well-known that large structures are required to generate power with competitive prices. The airflow generated in small structures can be used to dry agricultural products.
Most works from literature use yearly averaged values of temperature, solar radiation, and heat fluxes to obtain the optimum dimensions that maximize the efficiency or power output and/or minimize the total cost. In our work, we use a mathematical model to determine hourly solar radiation and ambient temperature and use these results to predict the airflow parameters for a given geometry. The geometry is then optimized to achieve maximum exergy efficiency. The model is simulated for a small-scale solar chimney 38]. What makes our work original is that the optimization was performed for one year, with a time step of one hour.

\section{MATHEMATiCAL MODEL}

\subsection{SYSTEM DESCRIPTION}

A typical solar chimney consists of a solar collector and a chimney (or tower). The geometry and schematics of the solar chimney are represented in Fig. 1. $D_{c}$ and $h_{c}$ are the diameter and height of the collector, and $D_{t}$ and $H_{t}$ are the diameter and height of the tower, respectively. A reference geometry was established, based on previous works from the authors ([3, 5, 39]), in which a prototype was built in Brazil. The smallscale pilot plant has a height and a diameter of $12.3 \mathrm{~m}$ and $1.0 \mathrm{~m}$, respectively. The diameter and height of the solar collector are $25.0 \mathrm{~m}$ and $0.5 \mathrm{~m}$, respectively. The dimensions were based on the dimensions of Manzanares prototype, in a scale of $1: 50$, adapted to have a minimum height from the ground.

\subsection{Problem statement}

Engineering Equation Solver (EES) was used to solve the model equations due to its reliable thermodynamic properties database and optimization techniques. The model consists of modelling the ambient conditions (ambient temperature and incident solar radiation) and the airflow parameters (mass flow rate, ground surface temperature, and outlet airflow temperature). The variables were determined on an hourly basis for the whole year. For each hour, steady-state conditions were assumed. The model is fully described in [38].

\subsubsection{ENVIRONMENTAL ANALYSIS}

The incident solar radiation and ambient temperature were predicted for Belo Horizonte city, Brazil

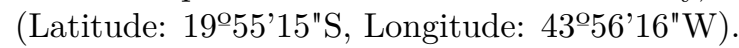

Incident solar radiation was predicted considering an isotropic sky, and average values from the literature for the clearness index to Belo Horizonte, Brazil [40, also used in 41. The absorbed solar radiation by the ground $S$ was considered to include beam radiation, isotropic diffuse radiation, and solar radiation diffusely reflected from the ground [42]. 


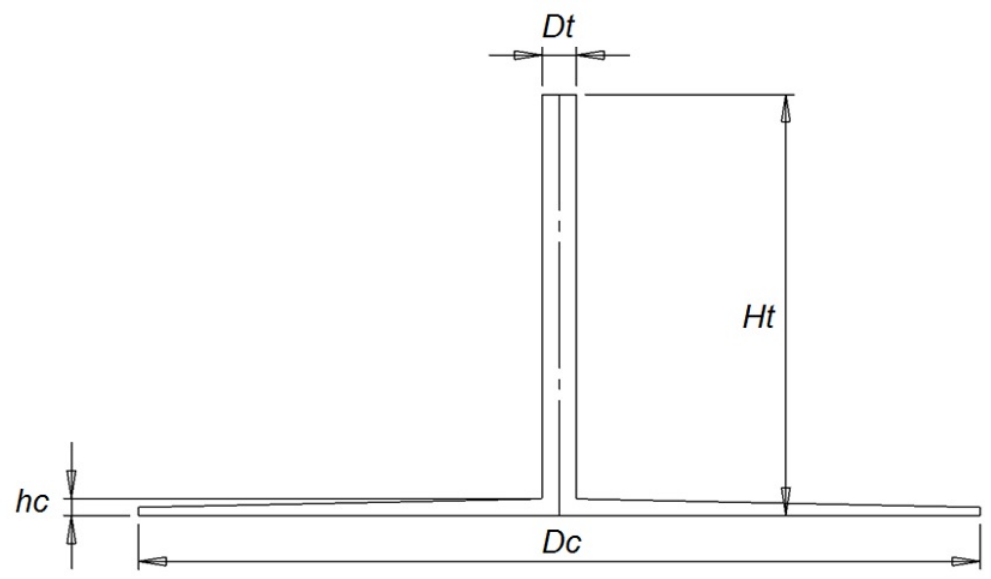

FiguRE 1. Main geometric parameters.

$$
\begin{aligned}
S=I_{b} R_{b}( & \tau \alpha)_{b}+I_{d}(\tau \alpha)_{d}\left(\frac{1+\cos \beta}{2}\right)+ \\
& +\rho_{\text {ground }} I(\tau \alpha)_{\text {groung }}\left(\frac{1-\cos \beta}{2}\right)
\end{aligned}
$$

$I$ represents the total solar radiation incident, given as the sum of the beam $\left(I_{b}\right)$ and diffuse $\left(I_{d}\right)$ components. The subscripts $b, d$, and ground refer to direct, diffused, and reflected by the ground types of radiation. $\rho_{\text {ground }}$ represents the ground reflectance. $\beta$ is the slope of the solar collector and $(\tau \alpha)$ is the transmittance-absorptance product. $R_{b}$ is a geometric factor, accounting for the ratio of beam radiation on the tilted surface to that on a horizontal surface at a given time. A detailed model for these parameters can be found in 42 .

Ambient temperature was determined according to 43, in which the daily period is subdivided into five intervals. The model assumes a correlation between the ambient temperature and the incident solar radiation, requiring the daily maximum, minimum, sunrise, and sunset temperatures, given by [43].

\subsubsection{AIRFLOW ANALYSIS}

An energy balance between the heat fluxes in the collector was performed. Part of the solar radiation absorbed by the ground $(S)$ is transferred to the deeper ground layers. The remaining is transferred to the airflow by convection, to the collector by radiation, and to the external environment by radiation. The heat fluxes were modelled using literature correlations, described in 38 .

The ground was assumed as a semi-infinite solid, since it extends to infinity, and the temperature variations occur only near the surface, as suggested by [44. Therefore, the initial temperature and the temperature at a point in a large distance from the surface are constant and considered as the annual average ambient temperature for the city of Belo Horizonte.
Koonsrisuk et al. 45 presented a model for the mass flow rate and outlet temperature of the flow as a function of the geometric parameters. For large solar chimneys, it is assumed that $D_{t}$ is significantly smaller than $D_{c}$. However, for small solar chimneys, the crosssectional area of the chimney cannot be neglected. Therefore, mass flow rate expression was modified to take into account the cross-sectional area, and it is represented by:

$$
\dot{m}=\sqrt[3]{\frac{\frac{\rho^{2} \beta^{\prime} g q_{\text {conv }, 1}^{\prime \prime} \pi^{3}}{8 C_{\text {pao }}} H_{t}\left[\left(\frac{D_{c}}{2}\right)^{2}-\left(\frac{D_{t}}{2}\right)^{2}\right]}{\frac{4 F_{y} H_{t}}{D_{t}^{5}}+\frac{\frac{F_{x}}{64}}{R_{c} h_{c}^{3}}+\frac{1}{D_{t}^{4}}}}
$$

$\beta^{\prime}$ is the volumetric expansion coefficient for real gases. $F_{x}$ and $F_{y}$ represent the friction factors in the collector and the tower, respectively [46].

The temperature of the airflow leaving the tower is given by [45], assuming adiabatic conditions:

$$
T_{a o}=\frac{q_{c o n v, 1}^{\prime \prime} \pi}{\dot{m} C_{p}}\left[\left(\frac{D_{c}}{2}\right)^{2}-\left(\frac{D_{t}}{2}\right)^{2}\right]+T_{a i}
$$

$\dot{m}$ is the mass flow rate.

\subsection{ENERGY AND EXERGY ANALYSIS}

The energy balance is used to determine the net heat rate $(\dot{Q})$. The mechanical work rate $\dot{W}$ is neglected, since there is no turbine in the system. $V_{a i}$ and $V_{a o}$ represent the inlet and outlet air velocity of the system, respectively. The specific enthalpies of the air in the inlet are $h_{a i}$ and outlet $h_{a o}$, respectively [47.

$$
\dot{Q}-\dot{W}=\sum \dot{m}_{a o}\left(h_{a o}+\frac{V_{a o}^{2}}{2}\right)-\sum \dot{m}_{a i}\left(h_{a i}+\frac{V_{a i}^{2}}{2}\right)
$$

According to [48, the solar chimney efficiency, neglecting the turbine, can be given by:

$$
\eta=\left[\frac{\int \dot{m} c_{p}\left(T_{a o}-T_{a i}\right) d t}{A_{c o l} H_{O}}\right]\left[\frac{H_{t} g}{C_{p} T_{a i}}\right]
$$


Where $c_{p}$ is the specific heat of air at constant pressure, $A_{c o l}$ is the area of the collector and $H_{O}$ is the extraterrestrial solar energy on a horizontal surface.

The exergy analysis was performed based on the mathematical model presented by [4]. The exergetic balance can be represented by:

$$
\sum\left(\dot{E} x_{\text {heat }}+\dot{E} x_{\text {mass }, \text { in }}\right)-\sum \dot{E} x_{\text {mass }, \text { out }}=\sum \dot{E} x_{\text {lost }}
$$

The first term represents the inlet exergy rate $\left(\dot{E} x_{i n}\right)$, due to heat ( $\left.\dot{E} x_{\text {heat }}\right)$ and to the air entering the system $\left(\dot{E} x_{m a s s, i n}\right)$. The second term is the outlet exergy rate ( $\left.\dot{E} x_{\text {out }}\right)$ due to the air leaving the system $\left(\dot{E} x_{\text {mass.out }}\right)$ and the last term represent the destroyed exergy rate $\left(\dot{E} x_{\text {lost }}\right)$ [49]. The exergy rates are presented in [38.

The exergy efficiency $\varepsilon$ is defined as the ratio of exergy outflow to exergy of inflow [50,52]:

$$
\varepsilon=1-\frac{\dot{E} x_{\text {lost }}}{\dot{E} x_{\text {in }}}=\frac{\dot{E} x_{\text {out }}}{\dot{E} x_{\text {in }}}=\frac{\dot{E} x_{\text {mass }, \text { out }}}{\dot{E} x_{\text {heat }}+\dot{E} x_{\text {mass }, \text { in }}}
$$

\section{Optimization}

Theoretical works about solar chimneys found in literature usually deal with only the analysis based on the first law of thermodynamics. Growing attention has been given to analyses using the second law of thermodynamics, which provide a more powerful tool for engineering assessments [53. The exergy analysis allows for identifying exergy losses due to irreversibilities in the processes. The yearly average exergy efficiency was chosen as the objective function to be maximized. The environmental conditions and airflow parameters used to determine the exergy efficiency were simulated on an hourly basis for the 365 days of the year.

The most important geometric parameters were considered as the optimization variables, and their ranges are:

$$
\begin{aligned}
10<D_{c}(\mathrm{~m}) & <100,0.1<h_{c}(\mathrm{~m})<1.0 \\
0.8<D_{t}(\mathrm{~m}) & <1.8,5.0<H_{t}(\mathrm{~m})<50
\end{aligned}
$$

The constraints applied to the problem were defined after a previous study on the influence of the geometry on the airflow parameters and exergy efficiency of small solar chimneys [54]. The parametric analysis developed on 54 showed that that the collector height does not significantly influence the airflow parameters, as long as it is kept at a minimum height from the ground. An increase of the collector diameter increases the average velocity and temperature, the tower diameter increases the mass airflow and the tower height increases the velocity and decreases the temperature.

There is no single optimization method that can be effectively applied to all problems [55]. The chosen method in a particular case depends on the characteristics of the objective function, the constraints on the nature and the number of variables. Therefore, the author recommends that more than one method is used in a comparative way. In this paper, the methods of conjugate directions and variable metric were used. Both methods are similar, but the conjugate directions method uses first-order information, resulting in lower computational efforts. The variable metric method has been shown to be a very powerful technique in non-linear optimization problems 56 .

\section{Results AND Discussion}

The results are divided into two sections. In the first section, optimization results are presented for two optimization methods. The objective function was the maximization of the yearly average exergy efficiency. The optimization variables were the main geometric parameters of the solar chimney. In the second section, the airflow and performance parameters throughout the year for the optimized and reference geometries are presented.

\subsection{Optimization Results}

Two optimization methods were used to evaluate the geometry that provides a higher exergy efficiency: variable metric and conjugate directions. The optimum dimensions found for both methods are presented in Table 1. The results of mass flow rate, ground surface temperature, outlet airflow temperature, solar chimney efficiency, and exergy efficiency are presented for the optimum geometry for both models. The model was simulated for the geometric parameters of the experimental prototype used as a reference. The results are also presented in Table 1. The optimum geometry is similar for both of the optimization models used. The tower height was slightly different between the models (a difference of approximately $5 \%$ ), causing small differences in the airflow parameters. The differences between the models' results can be attributed to the model structure. The optimum geometry presented higher mass flow rate and temperatures, resulting in a significant increase in the yearly average efficiencies.

\subsection{Monthly AVERAGE AIRFLOW PARAMETERS}

The airflow and performance parameters were evaluated on a monthly basis for the optimized geometry, for the optimization methods used. The results are presented in Figures 2 to 6 , compared to the results for the reference geometry.

Buoyancy forces generate the airflow inside the solar chimney. The air under the solar collector is heated by the ground surface, which is heated by the incident solar radiation. Therefore, solar radiation significantly affects the airflow parameters. The higher the levels of solar radiation, the higher the mass flow rate and temperatures. The monthly average mass flow rate throughout the year is presented in Figure 2. The general behaviour is the same as the solar radiation, higher during the summer and lower during the winter. Although it is expected that the mass flow rate varies 


\begin{tabular}{ccccc}
\hline Variables & Constraints & Reference geometry & Variable metric & Conjugate directions \\
\hline Collector diameter $[\mathrm{m}]$ & $10<D_{c}<100$ & 25.0 & 30.0 & 30.0 \\
Collector height $[\mathrm{m}]$ & $0.1<H_{c}<1.0$ & 0.5 & 0.5 & 0.5 \\
Tower diameter $[\mathrm{m}]$ & $0.8<D_{t}<1.8$ & 1.0 & 1.0 & 1.0 \\
Tower height $[\mathrm{m}]$ & $5.0<H_{t}<50$ & 12.3 & 17.9 & 18.8 \\
$\bar{\eta}_{\text {anual }}$ & - & 0.0040 & 0.1617 & 0.1638 \\
$\bar{\varepsilon}_{\text {anual }}$ & - & 0.1545 & 0.4416 & 0.4409 \\
$\bar{T}_{\text {aianual }}$ & - & 28.80 & 29.22 & 31.00 \\
$\bar{T}_{\text {ground }}$ anual & - & 28.44 & 31.01 & 1.59 \\
$\dot{m}_{\text {anual }}$ & - & 1.33 & 1.57 & \\
\hline
\end{tabular}

TABLE 1. Comparison of the results of the optimization methods.

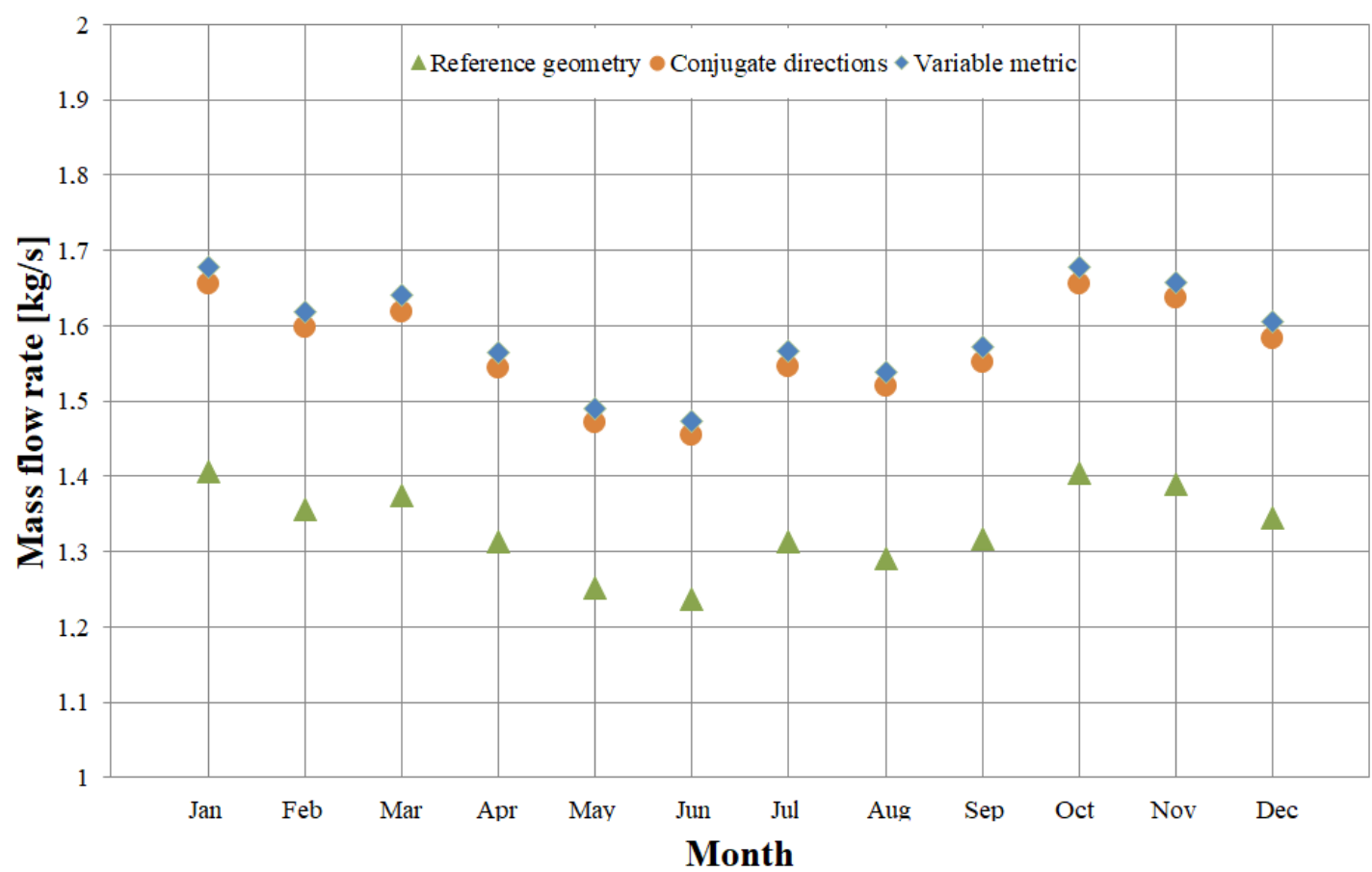

FiguRE 2. Variation of the mass flow rate throughout the year.

during the day, the monthly average values varied about $12 \%$ throughout the year for a defined geometry. It can be seen that the results obtained for the optimization methods were very close, slightly higher for the variable metric method. The mass flow rate obtained for the reference geometry was lower than the optimized geometry. This behaviour was already expected, because when the collector diameter and the tower height increase, the mass flow rate also increases, as seen in the literature [17, 22, 57, 58].

The monthly average ground surface temperature and outlet temperature are shown in Figures 3 and 4 The temperatures follow the same behaviour of the mass flow rate and solar radiation, with higher values in the summer and lower values in the winter. There are no significant differences between optimized and reference geometries since the ground surface temperature has a little influence on the geometrical parameters.
The outlet airflow temperature is more affected by geometry than the ground surface temperature. Therefore, higher differences were found when comparing the results from the optimized geometry to the results from the reference geometry. Since the optimized geometry presented higher tower height and collector diameter, higher airflow temperatures were obtained. It is worth noting that, as expected, ground surface temperatures are higher than airflow temperatures.

The monthly average solar chimney efficiency is shown in Figure 5 Higher efficiencies were found during the winter. This behaviour can be explained by the definition of the solar chimney's efficiency. During the winter, the incident solar radiation and ambient temperature are lower, and the outlet temperature is higher. Since the variations of solar radiation and ambient temperature are more significant than the variations of the outlet temperature, the solar chimney efficiency increases. Similar results were found for both optimization models since the geometry is similar. 


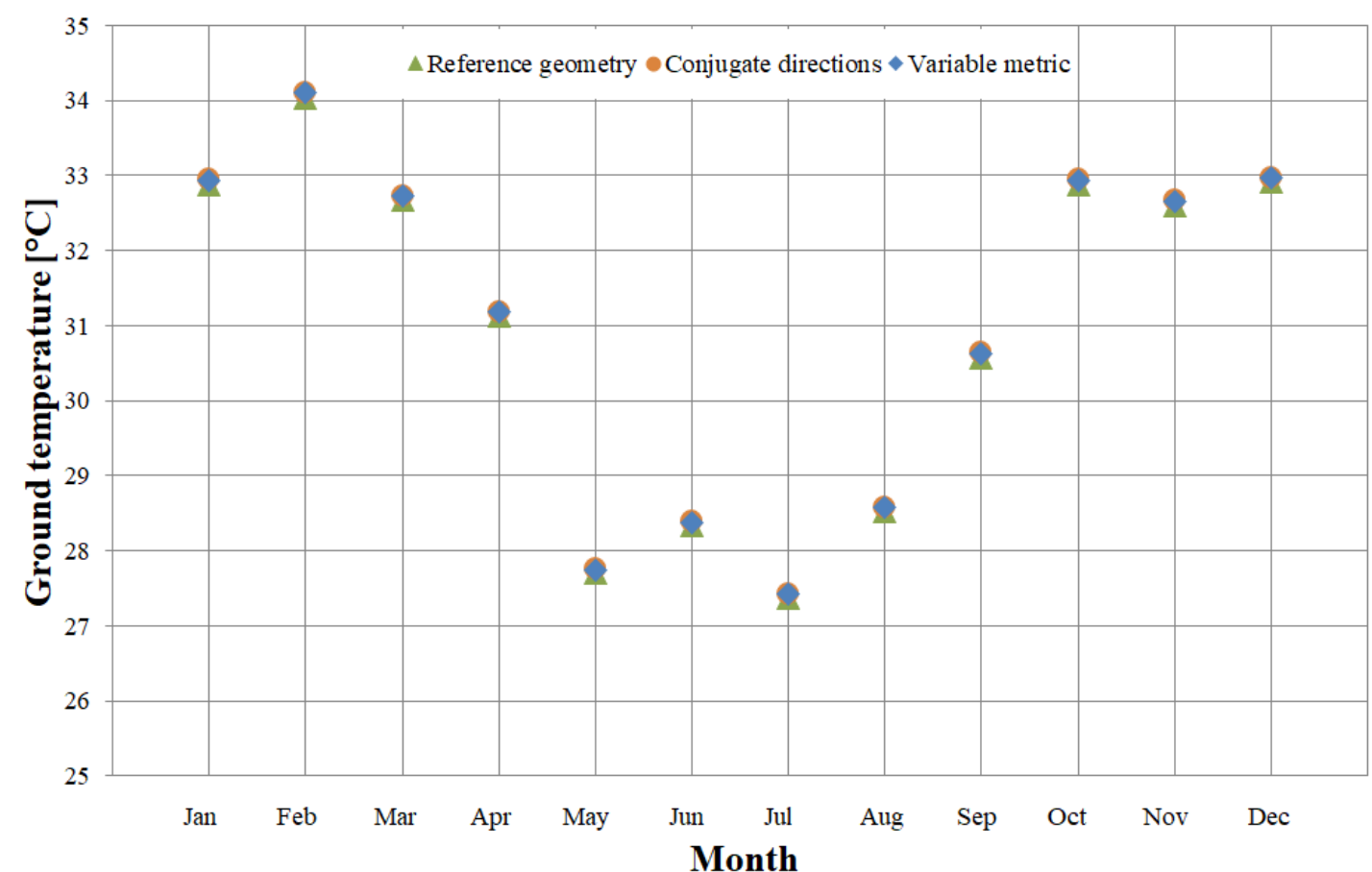

Figure 3. Variation of the ground temperature throughout the year.

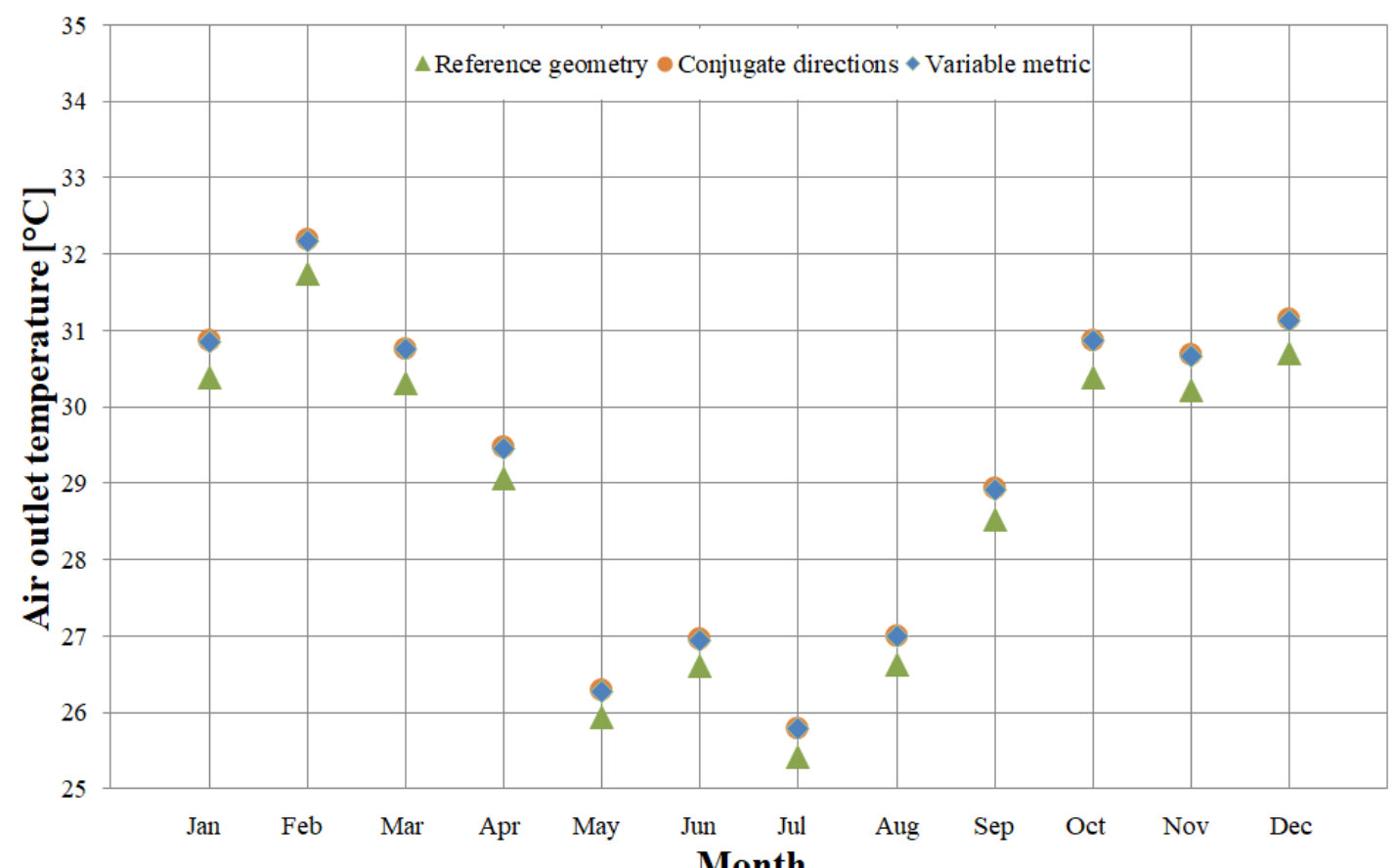

FIGURE 4. Variation of the air outlet temperature throughout the year. 


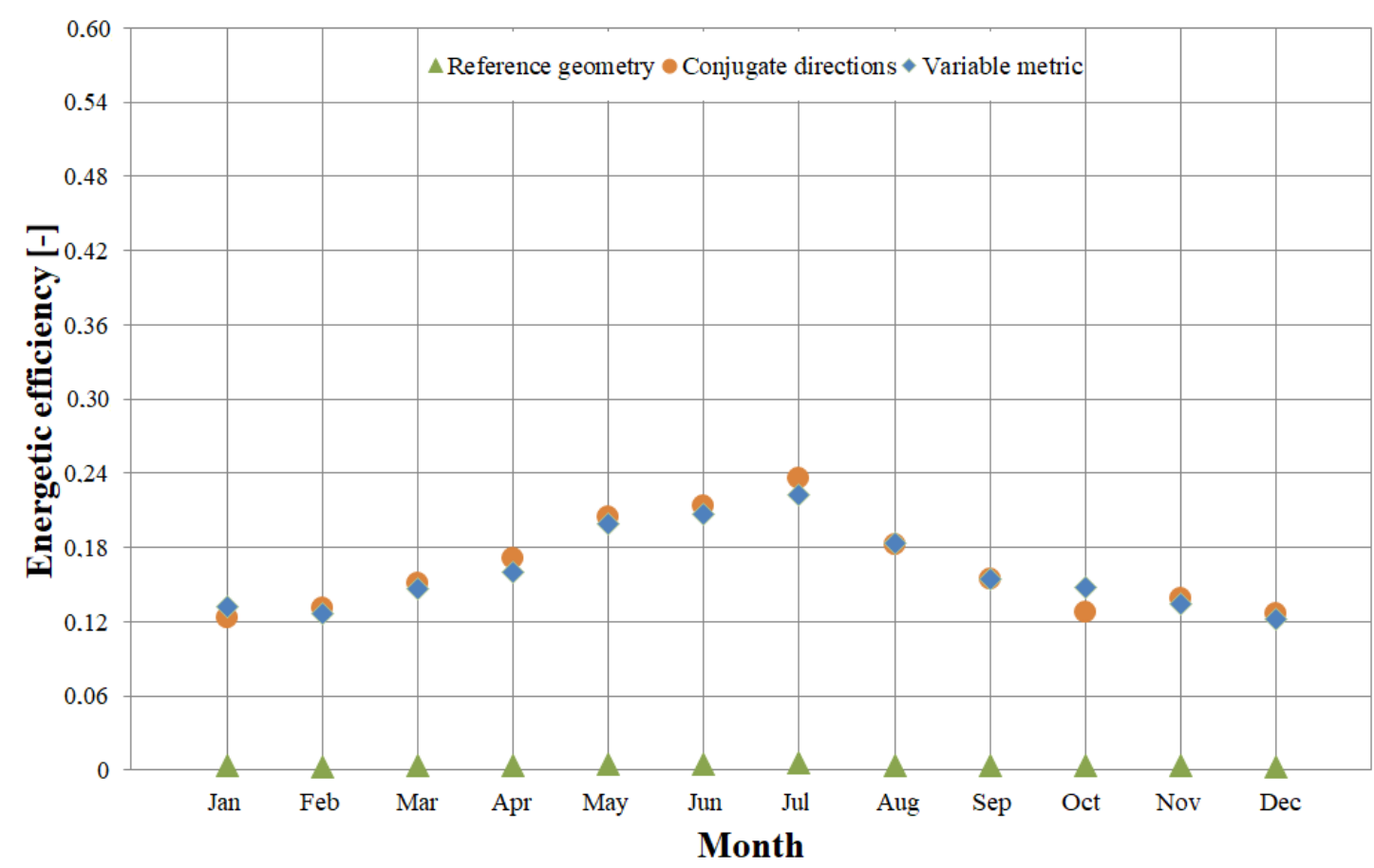

FiguRE 5. Variation of the solar chimney efficiency rate throughout the year.

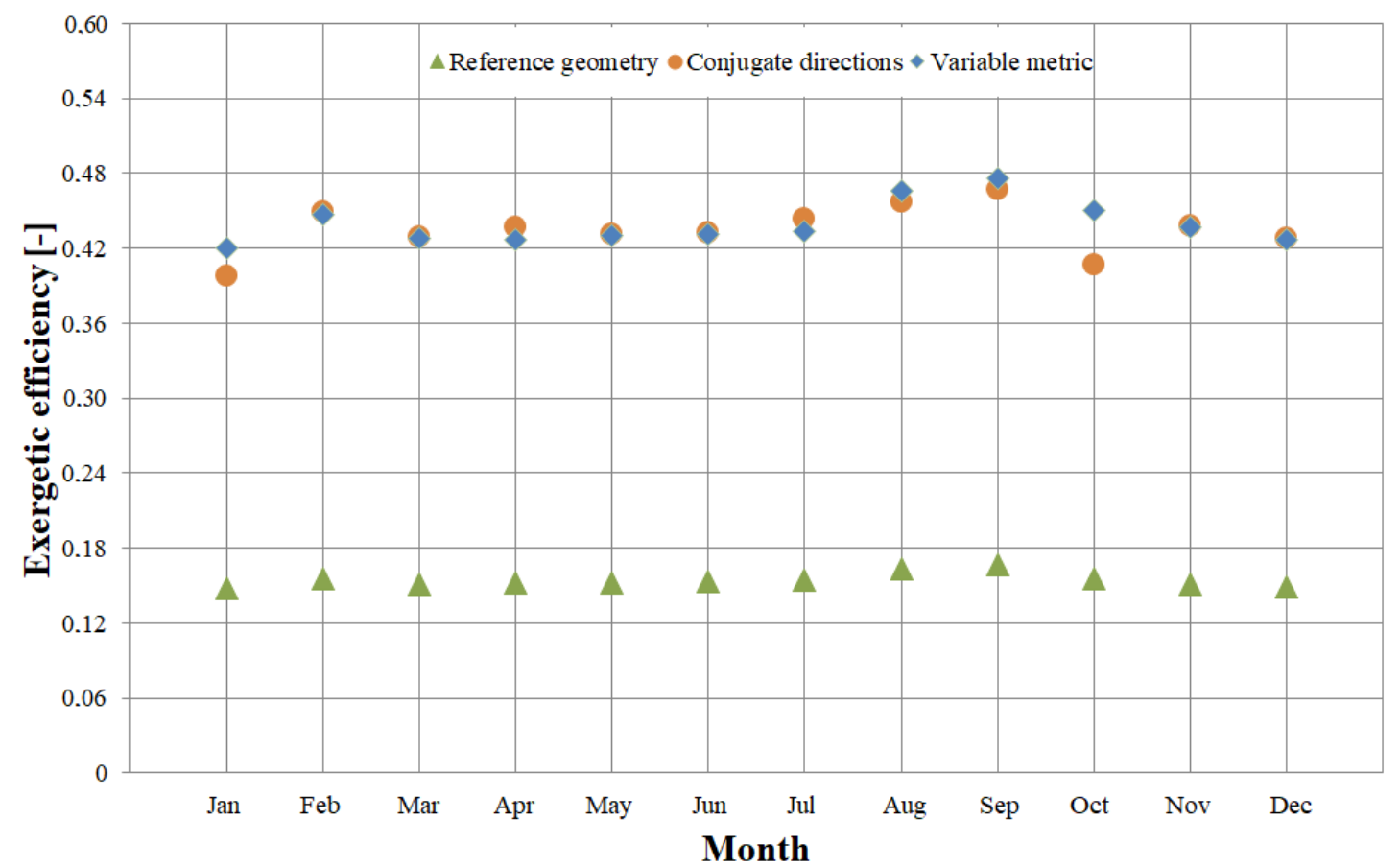

FiguRE 6. Variation of the exergy efficiency throughout the year. 
The reference geometry presented very low efficiency, ranging from $0.3 \%$ to $0.5 \%$. The efficiency for the optimized geometry increased significantly, ranging from $12 \%$ to $23 \%$. This difference can be attributed mainly to the geometry. The chimney height has the greatest influence on the solar chimney efficiency [48, and it was significantly increased during the optimization process.

The monthly average exergy efficiency is presented in Figure 6. Higher values were found for the optimized geometry since the objective function used in this paper was its maximization. The exergy efficiency is defined as the ratio between the outlet and inlet exergy rates. During the summer, higher solar radiation levels are found, increasing the outlet temperatures. Therefore, both outlet and inlet exergy rates increase during the winter, and the monthly average exergy efficiency has small variations throughout the year. Again, both optimization methods presented similar results.

\section{Conclusions}

An unsteady theoretical model was used to determine the airflow and performance parameters of a smallscale solar chimney. Results were obtained for a oneyear simulation, with a time-step of one hour. The geometry of the solar chimney was optimized to ensure the maximum yearly average exergy efficiency. Two optimization methods were used and the results were compared to those expected in a reference geometry, based on an experimental prototype. Monthly average values of the parameters were also evaluated. The following conclusions can be drawn from the analysis.

- The mathematical model was able to appropriately predict the parameters. The mass airflow equation should be better investigated, since the results were lower than experimental values;

- The solar chimney efficiency is higher in the winter and lower in the summer;

- The exergy efficiency does not present significant variations throughout the year;

- The optimum geometry showed great influence on the airflow parameters and on the energetic and exergetic efficiencies. The mass flow rate presented an average increase of $20 \%$ when compared to the reference geometry, and the outlet temperature was increased by about $1^{\circ} \mathrm{C}$.

- The energetic efficiency was stignificantly increased, mainly due to the increase of the chimney height;

- The optimization process was able to significantly increase the yearly average exergy efficiency when compared to the reference geometry;

- The optimization methods presented similar results, both for the geometry and the airflow and performance parameters. In future works, other optimization methods should be applied.

\section{ACKNOWLEDGEMENTS}

The authors are thankful to CNPq, Fapemig and PUC Minas. This study was financed in part by the Coordenação de Aperfeiçoamento de Pessoal de Nível Superior - Brasil (CAPES) - Finance Code 001

\section{LIST OF SYMBOLS}

$A_{c}$ ol Area of the collector

$C_{p} \quad$ Air specific heat

$C_{\text {pao }}$ Air specific heat at the tower outlet

$D_{c}$ Collector diameter

$D_{t}$ Tower diameter

$\dot{E} x_{\text {heat }}$ Exergy rate due to heat

$\dot{E} x_{i n}$ Inlet exergy rate

$\dot{E} x_{\text {lost }}$ Destroyed exergy rate

$\dot{E} x_{\text {mass,in }}$ Exergy rate due to the air entering the system

$\dot{E} x_{\text {mass,out }}$ Exergy rate due to the air leaving the system

$\dot{E} x_{\text {out }}$ Outlet exergy rate

$F_{x}$ Friction factor in the collector

$F_{y}$ Friction factor in the tower

$g$ Gravity acceleration

$h_{a i}$ Specific enthalpy of the airflow at the collector inlet

$h_{a o}$ Specific enthalpy of the airflow at the tower outlet

$h_{c}$ Collector height

$H_{\mathrm{o}}$ Extra-terrestrial solar energy on a horizontal surface

$H_{t}$ Tower height

I Total solar radiation

$I_{b} \quad$ Beam component of the solar radiation

$I_{d}$ Diffuse component of the solar radiation

$\dot{m}$ Mass flow rate

$\dot{Q}$ Heat transfer rate

$q_{c o n v, 1}^{\prime \prime}$ Convective heat transfer rate between the ground and the airflow

$R_{b} \quad$ Geometric factor

$S$ Solar radiation absorbed by the ground

$T_{a i}$ Temperature of the airflow at the collector inlet

$T_{a o}$ Temperature of the airflow at the tower outlet

$T_{\text {ground }}$ Ground surface temperature

$V_{a i}$ Velocity of the airflow at the collector inlet

$V_{a o}$ Velocity of the airflow at the tower outlet

$\dot{W}$ Mechanical work rate

$\beta \quad$ Slope of the solar collector

$\beta^{\prime} \quad$ Volumetric expansion coefficient

$\varepsilon \quad$ Exergy efficiency

$\eta \quad$ Solar chimney efficiency

$\rho \quad$ Air density

$\rho_{\text {ground }}$ Ground reflectance

$(\tau \alpha)$ Transmittance-absorptance product

\section{REFERENCES}

[1] N. Fathi, S. S. Aleyasin, P. Vorobieff. Numerical-analytical assessment on Manzanares prototype. Applied Thermal Engineering 102:243 - 250, 2016. DOI:10.1016/j.applthermaleng.2016.03.133.

[2] A. B. Kasaeian, S. Molana, K. Rahmani, D. Wen. A review on solar chimney systems. Renewable and Sustainable Energy Reviews 67:954 - 987, 2017. DOI:10.1016/j.rser.2016.09.081 
[3] A. G. Ferreira, C. B. Maia, M. F. B. Cortez, R. M. Valle. Technical feasibility assessment of a solar chimney for food drying. Solar Energy 82:198-205, 2008. DOI:10.1016/j.solener.2007.08.002

[4] C. Maia, J. Castro Silva, L. Cabezas-Gómez, et al. Energy and exergy analysis of the airflow inside a solar chimney. Renewable and Sustainable Energy Reviews 27:350 - 361, 2013. DOI:10.1016/j.rser.2013.06.020

[5] C. B. Maia, A. G. Ferreira, L. Cabezas-Gómez, et al. Thermodynamic analysis of the drying process of bananas in a small-scale solar updraft tower in Brazil. Renewable Energy 114:1005 - 1012, 2017. DOI:https://doi.org/10.1016/j.renene.2017.07.102

[6] L. Zuo, Y. Zheng, Z. Li, Y. Sha. Solar chimneys integrated with sea water desalination. Desalination 276:207-213, 2011. DOI:10.1016/j.desal.2011.03.052.

[7] L. Zuo, Y. Yuan, Z. Li, Y. Zheng. Experimental research on solar chimneys integrated with seawater desalination under practical weather condition.

Desalination 298:22-33, 2012.

DOI:10.1016/j.desal.2012.05.001

[8] T. Ming, T. Gong, R. Kiesgen de Richter, et al. Freshwater generation from a solar chimney power plant. Energy Conversion and Management 113:189-200, 2016. DOI:10.1016/j.enconman.2016.01.064

[9] T. Ming, T. Gong, R. Kiesgen de Richter, et al. Numerical analysis of seawater desalination based on a solar chimney power plant. Applied Energy pp. 1258-1273, 2017. DOI:10.1016/j.apenergy.2017.09.028

[10] T. Ming, T. Gong, R. Kiesgen de Richter, et al. A moist air condensing device for sustainable energy production and water generation. Energy Conversion and Management 138:638-650, 2017. DOI:10.1016/j.enconman.2017.02.012

[11] M. Asayesh, A. Kasaeian, A. Ataei. Optimization of a combined solar chimney for desalination and power generation. Energy Conversion and Management 150:72-80, 2017. DOI:10.1016/j.enconman.2017.08.006

[12] C. B. Maia, F. V. M. Silva, V. L. C. Oliveira, L. L. Kazmerski. An overview of the use of solar chimneys for desalination. Solar Energy 183:83 - 95, 2019. DOI:10.1016/j.solener.2019.03.007.

[13] L. Zuo, L. Ding, Y. Yuan, et al. Research progress on integrated solar chimney system for freshwater production. Global Energy Interconnection 2:214 - 223, 2019. DOI:10.1016/j.gloei.2019.07.014

[14] S. Patel, D. Prasad, M. R. Ahmed. Computational studies on the effect of geometric parameters on the performance of a solar chimney power plant. Energy Conversion and Management 77:424-431, 2014. DOI:10.1016/j.enconman.2013.09.056

[15] E. Cuce, H. Şen, P. M. Cuce. Numerical performance modelling of solar chimney power plants: Influence of chimney height for a pilot plant in Manzanares, Spain. Sustainable Energy Technologies and Assessments 39:100704, 2020. DOI:10.1016/j.seta.2020.100704

[16] M. Ghalamchi, A. Kasaeian, M. Ghalamchi. Experimental study of geometrical and climate effects on the performance of a small solar chimney. Renewable and Sustainable Energy Reviews 43:425-431, 2015. DOI:10.1016/j.rser.2014.11.068.
[17] M. Ghalamchi, A. Kasaeian, M. Ghalamchi, S. Mirzahosseini. An experimental study on the thermal performance of a solar chimney with different dimensional parameters. Renewable Energy 91:477-483, 2016. DOI:10.1016/j.renene.2016.01.091

[18] P. Guo, J.-Y. Li, Y. Wang, Y. Wang. Numerical study on the performance of a solar chimney power plant. Energy Conversion and Management 105:197205, 2015. DOI:10.1016/j.enconman.2015.07.072

[19] S. Hu, D. Leung, J. Chan. Impact of the geometry of divergent chimneys on the power output of a solar chimney power plant. Energy 120:1-11, 2017. DOI:10.1016/j.energy.2016.12.098

[20] D. Toghraie, A. Karami, M. Afrand, A. Karimipour. Effects of geometric parameters on the performance of solar chimney power plants. Energy 162:1052-1061, 2018. DOI:10.1016/j.energy.2018.08.086.

[21] C. Okoye, U. Atikol. A parametric study on the feasibility of solar chimney power plants in North Cyprus conditions. Energy Conversion and Management 80:178-187, 2014. DOI:10.1016/j.enconman.2014.01.009

[22] C. Maia, A. Ferreira, R. Valle, M. Cortez.

Theoretical evaluation of the influence of geometric parameters and materials on the behavior of the airflow in a solar chimney. Computers \& Fluids 38:625-636, 2009. DOI:10.1016/j.compfluid.2008.06.005

[23] T. Tayebi, M. Djezzar. Numerical simulation of natural convection in a solar chimney. International Journal of Renewable Energy Research 2:712-717, 2012.

[24] T. Tayebi, M. Djezzar. Numerical analysis of flows in a solar chimney power plant with a curved junction. International Journal of Energy Science 3:280-286, 2013.

[25] T. Tayebi. Entropy generation analysis of convective airflow in a solar updraft tower power plant. Heat Transfer-Asian Research 48:3885-3901, 2019. DOI:10.1002/htj.21573

[26] T. Tayebi, M. Djezzar. Effect of varying ambient temperature and solar radiation on the flow in a solar chimney collector. International Journal of Smart Grid and Clean Energy 5:16-23, 2016. DOI:10.12720/sgce.5.1.16-23

[27] M. Najmi, A. Nazari, S. Mansouri, G. Zahedi. Feasibility study on optimization of a typical solar chimney power plant. Heat and Mass Transfer 48:475-485, 2012. DOI:10.1007/s00231-011-0894-5.

[28] H. Dehghani, A. Mohammadi. Optimum dimension of geometric parameters of solar chimney power plants A multi-objective optimization approach. Solar Energy 105:603-612, 2014. DOI:10.1016/j.solener.2014.04.006

[29] E. Gholamalizadeh, M. H. Kim. Thermo-economic triple-objective optimization of a solar chimney power plant using genetic algorithms. Energy 70:204-211, 2014. DOI:10.1016/j.energy.2014.03.115

[30] E. Gholamalizadeh, S. Mansouri. A comprehensive approach to design and improve a solar chimney power plant: A special case - Kerman project. Applied Energy 102:975-982, 2013. DOI:10.1016/j.apenergy.2012.06.012 
[31] K. Shirvan, S. Mirzakhanlari, M. Mamourian, N. Abu-Hamdeh. Numerical investigation and sensitivity analysis of effective parameters to obtain potential maximum power output: A case study on Zanjan prototype solar chimney power plant. Energy Conversion and Management 136:350-360, 2017. DOI:10.1016/j.enconman.2016.12.081.

[32] H. Allwörden, I. Gasser, M. Kamboh. Modelling, simulation and optimisation of general solar updraft towers. Applied Mathematical Modelling 64:265-284, 2018. DOI:10.1016/j.apm.2018.07.023

[33] O. Najm, S. Shaaban. Numerical investigation and optimization of the solar chimney collector performance and power density. Energy Conversion and Management 168:150-161, 2018. DOI:10.1016/j.enconman.2018.04.089

[34] H. Muhammed, S. Atrooshi. Modeling solar chimney for geometry optimization. Renewable Energy 138:212-223, 2019. DOI:10.1016/j.renene.2019.01.068

[35] R. Balijepalli, V. P. Chandramohan, K. Kirankumar. Optimized design and performance parameters for wind turbine blades of a solar updraft tower (SUT) plant using theories of Schmitz and aerodynamics forces. Sustainable Energy Technologies and Assessments 30:192-200, 2018. DOI:10.1016/j.seta.2018.10.001.

[36] A. Habibollahzade, E. Houshfar, P. Ahmadi, et al. Exergoeconomic assessment and multi-objective optimization of a solar chimney integrated with waste-to-energy. Solar Energy 176:30 - 41, 2018. DOI:10.1016/j.solener.2018.10.016

[37] K. Rahbar, A. Riasi. Performance enhancement and optimization of solar chimney power plant integrated with transparent photovoltaic cells and desalination method. Sustainable Cities and Society 46:101441, 2019. DOI:10.1016/j.scs.2019.101441

[38] J. O. Castro Silva, T. S. Fernandes, S. de M. Hanriot, et al. A model to estimate ambient conditions and behavior of the airflow inside a solar chimney. In Renewable Energy in the Service of Mankind, vol. 2. 2016.

[39] C. Maia, A. Ferreira, R. Valle, M. Cortez. Analysis of the airflow in a prototype of a solar chimney dryer. Heat Transfer Engineering 30:393-399, 2009. DOI:10.1080/01457630802414797

[40] A. P. C. Guimarães. Estudo solarimétrico com base na definição de mês padrão e seqüência de radiação diária. UFMG, 1995.

[41] C. Maia, A. Ferreira, S. Hanriot. Evaluation of a tracking flat-plate solar collector in brazil. Applied Thermal Engineering 73:953-962, 2014. DOI:10.1016/j.applthermaleng.2014.08.052.

[42] J. A. Duffie, W. A. Beckman. Solar Engineering of Thermal Processes. John Wiley \& Sons Inc, 2013.

[43] Meteotes. Meteonorm - global meteorological database. http://meteonorm.com/, 2012.

[44] C. B. Maia. Análise Teórica e Experimental de uma Chaminé Solar: Avaliação Termofluidodinâmica. Universidade Federal de Minas Gerais, 2005.
[45] A. Koonsrisuk, S. Lorente, A. Bejan". Constructal solar chimney configuration. International Journal of Heat and Mass Transfer 53:327-333, 2010. DOI:10.1016/j.ijheatmasstransfer.2009.09.026

[46] D. G. Kröger, M. Burger. Experimental convection heat transfer coefficient on a horizontal surface exposed to the natural environment. In Proceedings of the ISES EuroSun2004 International Sonnenforum, vol. 1, pp. 422 - 430. 2004.

[47] I. Dincer, M. A. Rosen. Exergy, environment and sustainable development. In EXERGY, pp. 36 - 59. 2007.

[48] S. Nizetic, Sandro, Ninic, et al. Analysis and feasibility of implementing solar chimney power plants in the Mediterranean region. Energy 33:1680-1690, 2008. DOI:10.1016/j.energy.2008.05.012.

[49] A. Hepbasli. A key review on exergy analysis and assessment of renewable energy resources for sustainable future. Renewable and Sustainable Energy Reviews 12:593-661, 2008. DOI:10.1016/j.rser.2006.10.001.

[50] A. R. Celma, F. Cuadros. Energy and exergy analyses of OMW solar drying process. Renewable Energy 34(3):660-666, 2009. DOI:10.1016/j.renene.2008.05.019.

[51] S. Sevik, M. Aktaş, E. Dolgun, et al. Performance analysis of solar and solar-infrared dryer of mint and apple slices using energy-exergy methodology. Solar Energy 180:537-549, 2019. DOI:10.1016/j.solener.2019.01.049

[52] N. Aviara, L. Onuoha, O. Falola, J. Igbeka. Energy and exergy analyses of native cassava starch drying in a tray dryer. Energy 73:809-817, 2014. DOI:10.1016/j.energy.2014.06.087

[53] M. Aghbashlo, H. Mobli, S. Rafiee, A. Madadlou. A review on exergy analysis of drying processes and systems. Renewable and Sustainable Energy Reviews 22:1-22, 2013. DOI:10.1016/j.rser.2013.01.015

[54] J. de O. Castro Silva. Modelagem do escoamento de ar e otimização de uma chaminé solar. Pontifícia Universidade Católica de Minas Gerais, 2014.

[55] J. R. Shewchuk, et al. An introduction to the conjugate gradient method without the agonizing pain. Carnegie-Mellon University, 1994.

[56] F. Kowsary, K. Pooladvand, A. Pourshaghaghy. Regularized variable metric method versus the conjugate gradient method in solution of radiative boundary design problem. Journal of Quantitative Spectroscopy and Radiative Transfer 108:277-294, 2007. DOI:10.1016/j.jqsrt.2007.03.007.

[57] J. Oliveira Castro Silva, S. Hanriot, C. Maia. Parametric analysis of geometric configurations of a small-scale solar chimney. Advanced Materials Research 1051:975-979, 2014. DOI:10.4028/www.scientific.net/AMR.1051.975.

[58] K. Cherif, F. Ferroudji, M. Ouali. Analytical modeling and optimization of a solar chimney power plant. International Journal of Engineering Research in Africa 25:78-88, 2016.

DOI:10.4028/www.scientific.net/JERA.25.78 